\title{
Past, Present and Future: Urgency of Dealing with Climate Change
}

\author{
Alan D. Hecht \\ Office of Research and Development, US Environmental Protection Agency, Washington DC, USA \\ Email: Hecht.Alan@EPA.gov
}

Received 10 September 2014; revised 20 October 2014; accepted 3 November 2014

Academic Editor: Qiang Zhang, Sun Yat-sen University, China

Copyright (C) 2014 by author and Scientific Research Publishing Inc.

This work is licensed under the Creative Commons Attribution International License (CC BY).

http://creativecommons.org/licenses/by/4.0/

(c) (i) Open Access

\section{Abstract}

This paper gives an historic perspective on 10 critical phases and actions in advancing an understanding of climate change and taking appropriate domestic and international action. Credit goes to atmospheric scientists for their committed efforts to understand, model and measure the impacts of climate change. Today, greenhouse gases are at a record level and little doubt remains that greenhouse gases (GHG) warm the atmosphere and that human-made climate change is real. Recognizing the urgency of responding to climate change, the 2013 US Climate Action Plan aims to cut carbon emissions and prepare to deal effectively with the economic, social, and environmental impacts of climate change. Many US states, Tribes, and local communities have also begun to take action to reduce GHG emissions and adapt to the impact of climate change, especially on disadvantaged communities. While recognition of the urgency of action on climate change is growing in government and in large parts of the business and financial sector, it has taken over 40 years to get to this point. While an understanding of the reality and impact of climate change has grown, significant efforts to reduce the concentration of greenhouse gases in the atmosphere and stabilize global warming have not occurred. The problem that society faces is not the absence of scientific knowledge, but rather the need to reduce GHG emissions and create resilient and adaptive responses to climate change. This paper concludes that future successes will need more effective collaboration between government, business, and society to address climate change and greater public understanding of the impacts of climate change on human health and economic well-being.

\section{Keywords}

Climate Change, Atmospheric Science, Resilience, Climate Adaptation 


\section{Introduction}

Debate over the cause and impacts of climate change has gone on for decades. Today, there is little doubt that greenhouse gases warm the atmosphere and that human-induced climate change is real. Greenhouse gases in the atmosphere today are at a record level being just below 400 parts per million about 40 percent higher than in pre-industrial times. Many actions are now underway to enhance an understanding of the full impacts of climate change and to create resilient and adaptive responses. Actions by federal agencies to respond to climate change are called for in Executive Order (EO) 13653 and the US Climate Action Plan issued by President Obama in 2013.

A major challenge facing society and a key theme of this paper is building consensus within federal and state governments and between government and industry on how best to anticipate, respond, and adapt to continuing changes in climate. As history shows, such collaboration is often hard to achieve but is absolutely necessary to address the cause and impacts of climate change. Hence, a key goal of the EO 13653 and the US Climate Action Plan is for the federal government to work with state and local government and tribal leaders on designing and implementing effective and resilient responses to impacts of climate change.

Toward accomplishing this objective, the Climate Action Plan invokes partnerships as a critical means to develop systems that are more resilient to climate change. A key goal of the plan is to remove policy barriers, modernize programs, and establish a short-term task force of state, local, and tribal officials to advise the federal government on key actions in support of local and state efforts to prepare for climate change. In particular, the plan calls for innovative strategies in regions such as those affected by Superstorm Sandy to develop knowledge about strengthening communities against future extreme weather and other climate impacts. The action plan also aims to deliver specific science-based knowledge to government and specific private sectors to help them understand, prepare for, and reduce the impacts of climate change.

Supporting the Climate Action Plan, EPA has proposed regulations that it forecasts will reduce carbon emissions from the electricity sector by 30 percent by 2030. EPA's primary objective is to reduce the emissions intensity of existing electricity-generating sources. The new regulations are based on Section 111(d) of the Clean Air Act, which allows states to develop their own plans to meet emission targets for power plants in several ways, including upgrading plants, switching from coal to natural gas, increasing demand-side energy efficiency, and generating additional renewable energy.

While the urgency of taking action on climate change is now apparent to federal and many states, tribal, and local governments and to a large part of the business and financial sector, it has taken over 40 years to get to this point. This paper gives an historic perspective on 10 critical phases and actions in advancing an understanding of climate change and taking appropriate domestic and international action (Table 1).

Unfortunately, while an understanding of the reality and impact of climate change has grown, significant actions to reduce the growth of greenhouse gases have not occurred (see Figure 1).

\section{1960-1970s: Understanding the Science of Climate Change}

In the early 1970s, public concern about changing weather patterns and long-term climate change began to

Table 1. Identifies critical phases and actions in response to climate change.

$\begin{array}{ll}\text { 1960s-1970s: } & \text { Understanding the Science of Climate Change } \\ \text { 1978: } & \text { Creating the National Climate Program Act and the US Global Change Research Program } \\ \text { 1980s: } & \text { Assessing and Evaluating Climate and Energy } \\ \text { 1988: } & \text { Creating the Intergovernmental Panel on Climate Change } \\ \text { 1990: } & \text { Preparing the First IPCC Report } \\ \text { 1992: } & \text { Negotiating the UN Framework Convention on Climate Change } \\ \text { 1997: } & \text { Fighting the Climate Wars } \\ \text { 2000-2010: } & \text { Regulating CO } 2 \text { as a Pollutant: The Supreme Court Decision } \\ \text { 2007: } & \text { Responding to Extreme Events, the } 2013 \text { IPCC Assessment Report, and the } 2014 \text { US Climate Report } \\ \text { 2010s: } & \end{array}$




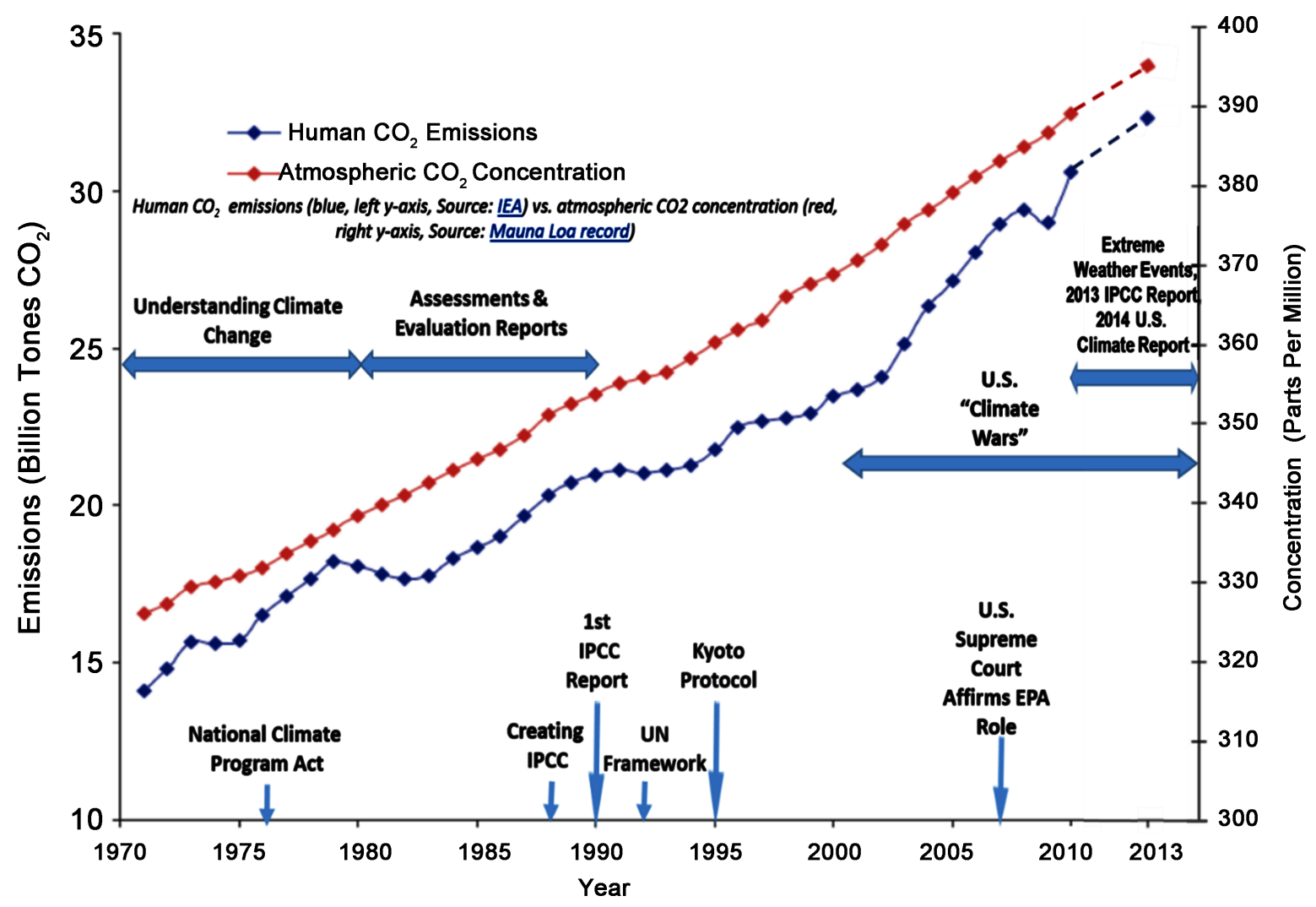

Figure 1. Global $\mathrm{CO}_{2}$ emissions and concentrations continue to increase from 1975 to 2013. (Prepared by frank princiotta of EPA)

emerge. In the thirty years leading up to the 1970s, temperature recordings suggested the presence of global cooling. Yet at the same time, more scientists were concerned that the growing amount of GHGs humans were putting into the atmosphere would cause much greater warming. Extensive drought conditions in Africa and the US further raised questions about the ability of humans to affect climate.

The threat of warming began to get political attention. Generally unknown at the time, President Nixon's advisor Daniel Patrick Moynihan sent a memo on September 19, 1969, to chief of staff John Ehrlichman, identifying climate change as a potentially serious environmental problem. Moynihan was responding to the widespread suffering caused by drought in Sub-Saharan Africa from 1968 to 1972 . Drought had also reduced grain production in the Soviet Union, China, Eastern Europe, and Latin America, causing grain prices to increase dramatically worldwide, stressing food-importing countries and hampering African relief efforts.

Recognizing the potential impact of climate change, Moynihan warned that atmospheric concentration of carbon dioxide would rise by 25 percent by the year 2000, resulting in a $7^{\circ} \mathrm{F}$ increase in temperature and 10 -foot rise in sea level. Although emissions increased by $50 \%$ in this period, temperature increase and sea level rise were fortunately far less than Moynihan’s projections. Moynihan suggested to Nixon that climate change "is a subject that the Administration ought to get involved with" [1].

One other root of scientific and political focus on climate change came from the potential military use of weather modification. The idea of weather modification was advanced by the famous mathematician John von Neumann, who organized a meeting in Princeton in 1945 to explore whether weather modification could make a difference in the next war. In one scenario, weather modification could affect Soviet harvests by causing drought and thus limiting the economic activity and social well-being of the USSR.

In a 1955 Fortune magazine article, von Neumann wrote, "Microscopic layers of colored matter spread on an icy surface, or in the atmosphere above one, could inhibit the reflection-radiation process, melt the ice, and change the local climate... The effects could be far-reaching, even worldwide.” Von Neumann foresaw "forms of climatic warfare as yet unimagined,” perhaps more dangerous than nuclear war itself. He hoped such a prospect would 
force humanity to take "a new, global approach to its political problems" [2].

The possibility of human-induced climate change, largely driven from greenhouse gases on the atmosphere, led to an early warning in 1965 from the Environmental Pollution Board of the President Johnson's Science Advisory Committee that we "will modify the heat balance of the atmosphere to such an extent that marked changes in climate could occur." Reacting to this in a special message to Congress in February 1965, Johnsonsaid "this generation has altered the composition of the atmosphere on a global scale through... a steady increase in carbon dioxide from the burning of fossil fuels" [3].

How did atmospheric scientists respond to these growing threats? What critical research was needed to understand the full impact of potential climate change? A major climate conference at Brown University in1972 focused on both the causes of past ice ages and growing concern about possible impacts on climate from particulate matter and greenhouse gases and hence global warming. A major impetus for this meeting was the broad recognition of the need for more research on climate change.

After the conference the conference organizers, (the late G. J. Kukla and R. K. Mathews) wrote to President Nixon (December 3, 1972) calling for federal action on possible climate change. At that time, with no consensus on climate change, their letter was an important impetus to expanding research. The letter noted that the "main conclusion of the meeting was that a global deterioration of climate, by order of magnitude larger than any hitherto experience by civilized mankind, is a very real possibility and indeed may be due very soon.” On the question of "artificial heating" of the atmosphere, as opposed to orbital changes for ice ages, the letter concluded that "knowledge necessary for understanding the mechanism of climate change is lamentably inadequate and the ultimate causes remain unknown" (Kukla and Mitchell, 1972) [4].

The White House assigned the letter to the Bureau of International Scientific and Technological Affairs of the State Department, which in turn passed it on to the Interdepartmental Committee for Atmospheric Sciences (ICAS) for its review and proposed actions. At that time the ICAS was the highest level interagency body within the US Government concerned with the atmospheric sciences. The panel sought advice on the issue from experts in the field and decided that the topic was of paramount importance, thus effectively supporting the creation of a national climate research program to address climate issues [5].

The ability to understand the impact of climate change requires an understanding of the physics and chemistry of the atmosphere and oceans. By early 1970, the US had established several major climate modeling centers, of which the first, the Geophysical Fluid Dynamic Laboratory (GFDL) of the National Oceanic and Atmospheric Administration (NOAA) located at Princeton University was established in 1955.

Another center was established by the National Science Foundation in 1960: the National Center for Atmospheric Research (NCAR) in Boulder, Colo. Besides these government laboratories, UCLA established a modeling laboratory, as did the RAND Corporation, focused on possible military applications of climate modification. The RAND center was ultimately funded by the Defense Advanced Research Projects Agency (DARPA), which had been created in 1958 in response to the Soviet launching of Sputnik, with the mission of keeping US military technology ahead of any potential enemy.

These centers were focused on developing atmosphere-ocean climate models of the possible reactions to global warming resulting from increased GHG emissions. In 1975, results from an early computer simulation of GHG-induced climate change at GFDL and a National Academy of Sciences (NAS) report (Understanding Climatic Change: A Program for Action) both underscored the need for better understanding and research on climate change. The introduction of the NAS report declared, "Climatic change has been a subject of intellectual interest for many years. However, there are now more compelling reasons for its study: the growing awareness that our economic and social stability is profoundly influenced by climate and that man's activities themselves may be capable of influencing the climate in possibly undesirable ways. The climates of the earth have always been changing, and they will doubtless continue to do so in the future. How large these future changes will be, and where and how rapidly they will occur, we do not know."

One other scientific group was also asserting the need for research on climate change. JASON—a group of top scientists with high-level security clearance who gathered annually to advise the US government-in 1979 wrote a report predicting that atmospheric carbon dioxide might double by 2035, resulting in mean global temperature increases of $2^{\circ} \mathrm{C}$ to $3^{\circ} \mathrm{C}$ and polar warming of as much as $10^{\circ} \mathrm{C}$ to $12^{\circ} \mathrm{C}$. The JASON report was supported by the National Academy of Sciences, which warned, "If carbon dioxide continues to increase, [we] find no reason to doubt that climate changes will result, and no reason to believe that these changes will be negligible" [6].

The strong global focus on atmospheric science research and the emerging threat of human-induced climate 
change also received attention at the 1979 World Climate Conference-organized by the World Meteorology Organization (WMO), which had been established in 1950 and now has over 100 member countries-which gave birth to the World Climate Program. In 1979 meteorologists from around the world saw an urgent need to "take full advantage of man's present knowledge of climate; take steps to improve significantly that knowledge; and to foresee and prevent potential man-made changes in climate that might be adverse to the well-being of humanity" [7]. Partnering with other international organizations, the WMO would later become an important driver for international negotiations for a climate agreement.

Hence, by the end of the decade, the focus on climate change was substantially growing; it would lead to several of the key events that follow, the first of which concerned the first US legislation to deal with climate change. What was first motivated by military interest in climate modification and global cooling was now clearly focused on global warming. Critical research was needed to understand the full impact of climate change.

\section{1978: Creating the National Climate Program Act and the US Global Change Research Program}

Combined and coordinated federal action on assessing and researching climate change was significantly advanced by the late Rep. George Brown of California who helped create an historic act creating the National Climate Program Act establishing a National Climate Program Office (NCPO) and an interagency Policy Board. President Carter signed the National Climate Program Act in 1978. The NCPA called for development of a 5-year federal plan to assess the "effect of climate on the natural environment, agricultural production, energy supply and demand, land and water resources, transportation, human health, and national security."

The Act had bipartisan Congressional support reflecting common understanding (reflected in the Preface of the Act) that "weather and climate change affect food production, energy use, water resources and other factors vital to national security and human welfare." And that "An ability to anticipate natural and man-induced changes in climate would contribute to the soundness of policy decisions in the public and private sectors."

Congress agreed at the time that "Information regarding climate is not being fully disseminated or used, and Federal efforts have given insufficient attention to assessing and applying this information" and that the "United States lacked a well-defined and coordinated program in climate-related research, monitoring, assessment of effects, and information utilization.”

The NCPO which had the ability to convene federal agencies to address climate change issues was later critical in proposing actions what would lead to the creation of the UN Intergovernmental Panel on Climate Change.

The first NCPO Five Year Climate Plan of 1980 laid out needed research across federal agencies. It is ironic that the context for the plan's in 1980 creation was extreme weather events similar to those that the US is facing following Superstorm Sandy and extensive drought in the western US.

Extreme climatic events in recent years have emphasized the central role of climate in human affairs. A series of droughts, freezes, and other climatic anomalies in many parts of the world in 1972 caused widespread crop failures. Large purchases of North American grain by the Soviet Union and other nations had serious economic repercussions. Severe winter weather in the Eastern and Midwestern United States in early 1977 caused many schools, industrial plants, and businesses to close, because not enough fuel was available for heating. The "Winter of "77" also brought frost damage to the Florida citrus crop and serious water shortages to drought-stricken regions of the western United States [8].

The NCPO was a critical first step in launching cooperation among federal agencies. It was later replaced by the US Global Change Research Program (USGCRP), which the Global Change Research Act of 1990 mandated in order to "assist the nation and the world to understand, assess, predict, and respond to human-induced and natural processes of global change".

The USGCRP (known as the US Climate Change Science Program from 2002 through 2008) is now a multiagency program coordinating the thirteen federal departments and agencies that participate in climate change research. It engages in a variety of activities aimed at strengthening and strategically directing climate change research in the United States and improving the flow of that information to federal, state, and local decisionmakers, and to the public.

USGCRP oversees international events, large-scale program elements, and smaller thematic interagency working groups and has been effective in preparing several major national assessments of the science and impacts of 
climate change. Its 2014 report affirms the reality of climate change and the need for immediate action (See Section 11).

\section{1980s: Assessing and Evaluating Climate and Energy}

Scientific understanding is a key driver of policy development. Throughout much of the 1980s, climate change was getting extensive domestic and international attention, as were national and international responses. While science may drive the need for change, policy action is also affected by economic, social, and political considerations.

In the last days of the Carter administration, the Council on Environmental Quality (CEQ) published Global Energy Futures and the Carbon Dioxide Problem (1981), which recognized the challenge:

People have altered the face of the planet throughout history, but the power of today's technology and our growing capacity to foresee, however uncertainly, the possible consequences of our acts put us in a new moral position. The responsibility for the $\mathrm{CO}_{2}$ problem is ours-we should accept it and act in a way that recognizes our role as trustees of the earth for future generations.

While presidents from Nixon and Ford through Carter and Reagan were sensitive to the emerging climate change issue, the concern in their administrations was tempered by the need to deal with problems in the national economy. Reagan, though hesitant to impose costly environmental rules, was an environmental leader with respect to protecting the ozone layer, taking the initiative to support the Montreal Protocol's phase-out of ozonedepleting chemicals, which was projected to cost much less than the alternative of taking no action.

Despite the economic decline, a few members of Congress were concerned about climate change and scientific uncertainty. Congress again turned to the NAS to write a report, Climate Change: Report of the Carbon Dioxide Assessment Committee (1983), which reaffirmed the prediction of long-term climate warming associated with increasing atmospheric $\mathrm{CO}_{2}$. Its report took a cautious approach toward policy: The NAS authors presented their conclusions as a "flashing yellow warning light" for policy makers:

We do not believe, however, that the evidence at hand about $\mathrm{CO}_{2}$-induced climate change would support steps to change current fuel-use patterns away from fossil fuels. Such steps may be necessary or desirable at some time in the future, and we should certainly think carefully about costs and benefits of such steps; but the very near future would be better spent improving our knowledge (including knowledge of energy and other processes leading to creation of greenhouse gases) than in changing fuel mix or use.

In 1983 EPA also published a critical report, Can We Delay a Greenhouse Warming? which aimed at assessing "whether specific policies aimed at limiting the use of fossils fuels would prove effective in delaying temperature increases over the next 120 years." The report was a red flashing light, raising the specter of a collision course between the need for energy derived from coal and global warming of potentially catastrophic proportions. The report said that climatic changes from greenhouse gases were unavoidable and warned that the United States and other countries must begin searching for ways to mitigate the impact. It concluded that even as drastic and unlikely a step as a total ban on burning coal would delay by only 15 years an increase of $3.6^{\circ} \mathrm{F}$ in average global temperatures (Seidel and Keyes, 1983) [9].

In Congress, Senators Chafee, Stafford, Bentsen, Durenberger, Mitchell, Baucus, Leahy, and Gore began to pressure the White House to take action on climate change. As concerns about climate change grew, Ronald Reagan in 1987 signed the first federal climate change legislation, the Global Climate Protection Act (P.L. 100 204.) This law authorized the State Department to develop an approach to address global warming and established an intergovernmental task force to develop a national strategy. At the state level, the next year the governors of California (George Deukmejian) and New Jersey (Thomas Kean) signed the first of many state laws to respond to climate change.

Congress also requested EPA to undertake two additional studies on impacts of climatic change and possible options in response to greenhouse warming. The first study, published in 1989, examined the potential effects of climate change on the United States [10]. A second study, published in 1990, examined policy options to stabilize and reduce emissions of greenhouse gases. The latter report generated intense interagency debate because it identified the need for a broad spectrum of regulatory, fiscal, and education measures such as increased automobile efficiency, accelerated use of renewable energy, strengthened appliance standards, and carbon taxes [11]. 
By 1988, while the US economy had improved, the Upper Midwest suffered its worst drought in 50 years. Mounting pressure to deal with climate change was growing, driven by international activities that would lead to the creation of the IPCC.

\section{1988: Creating the Intergovernmental Panel on Climate Change}

Creation of the Intergovernmental Panel on Climate Change (IPCC) and publication of its first assessment of the impact of climate change were critical steps leading to the first international climate convention. The IPCC has since produced many reports reaffirming the potential impacts of climate change. While the IPCC and its work have been repeatedly attacked and criticized, its creation was one of the most important steps leading to domestic and international actions on climate change.

The origin of the IPCC traces back to the mid-1980s when three key international organizations- the World Meteorological Organization (WMO), the United National Environment Program (UNEP), and the International Council of Scientific Unions (ICSU)—were effectively shining a spotlight on climate change.

In a 1985 planning document accepting the reality of climate change, UNEP called for a convention on climate change, i.e., an international agreement. UNEP began to lead international scientific efforts to establish the foundation for negotiating an agreement on climate change and, in cooperation with the WMO and ICSU, a joint scientific convention on greenhouse gases in Villach, Austria. The conference report ("Assessment of the Role of Carbon Dioxide and of Other Greenhouse Gases in Climate Variations and Associated Impacts") published in 1986, had a big impact on the climate debate in the US.

In response to the recommendations of the Villach report, then UNEP Executive Director Mostafa Tolba sent a letter to Secretary of State George Schultz, urging the US to take appropriate actions. The State Department passed the letter to the NCPO to prepare an interagency response, which turned out to be one of the most important actions of the decade related to climate change.

The majority of federal agencies at that time did not support negotiating a climate convention. The view of senior officials in Washington was that the underlying scientific evidence for global warming was inconsistent, contradictory, and incomplete and did not justify policy actions that were seen as costly for the US economy.

Department of Energy (DOE) representatives felt strongly that the UNEP report was inadequate because government officials were not involved in its preparation, while EPA and the State Department supported the idea of a convention and suggested that perhaps it was timely for governments to prepare an international scientific assessment, especially in the light of conflicting scientific evidence.

The NCPO was able to strike a compromise among federal agencies. Since DOE was insisting on a government-led international scientific assessment, it was decided that such an internationally-led group should be established. This idea led to a US proposal responding to the UNEP letter for an intergovernmental "mechanism" to conduct a government-led, scientific assessment of the climate change issue. This mechanism later became the Intergovernmental Panel on Climate Change (IPCC). Creation of IPCC and publication of its first assessment of the impact of climate change were critical steps leading to the first international climate convention.

I was the NCPO director from 1981 to 1989 and with the help of the late Bo Döös played a significant role in resolving the interagency debate, as a Harvard study on the history of the IPCC described [12]:

The hub of activity was in the US, where a number of proposals were refined and discussed by the various agencies. Much of this process is still shrouded in mystery and by most accounts a large number of individuals at various US agencies including the State Department, DOE, and EPA played key roles. One proposal that bears some resemblance to the eventual form of the IPCC can be traced back to Alan Hecht, Bo Döös, and others at the NCPO. Döös, a Swedish meteorologist and former director of the World Climate Program, drew on his experience with the Intergovernmental Panel in the first GARP (Global Atmospheric Research Program) Global Experiment in the mid-1970s and proposed an "Intergovernmental Panel on the Assessment of Climate Change” on similar lines.

The proposal finally emerged after inputs from a number of U.S. agencies. The IPCC, a joint creation of UNEP and the World Meteorological Organization (WMO), came into being after lengthy US diplomacy in the WMO. Much international debate followed, but by the summer of 1988, the IPCC was born [13].

What makes the IPCC so critical was that it would prepare an internationally accepted scientific assessment which would be the foundation for the first international climate agreement signed by countries at the Rio Earth 
Summit in 1992. Without a strong recommendation for action from the IPCC report, the climate agreement would not have happened.

\section{1990: Preparing the First IPCC Report}

At the first IPCC meeting in November 1988, UNEP executive director Mostafa Tolba laid out the proposed structure that won international support. He proposed creation of work groups on scientific assessment, socioeconomic impacts, and policy responses. Debate followed on who would chair these groups. Consensus quickly converged on a widely respected Swedish meteorologist, Bert Bolin, who was elected chair of the IPCC with representatives of Saudi Arabia and Nigeria as vice chairs. John Houghton of the United Kingdom became chair of the IPCC working group on science. The chair of the impact assessment group was the late Yuri Izrael. Fred Bernthal of the US Department of State became chair of the policy responses working group.

From 1989 to August 1990, the IPCC working groups prepared their first assessment. Secretary of State James Baker spoke at the first meeting of the IPCC Working Group on Response Strategies, a 17-nation working group. He said that "the political ecology is now ripe for action". While scientists still must "refine the state of our knowledge" about the causes and effects of the threat, Baker said, "we can probably not afford to wait until all of the uncertainties have been resolved before we do act".

The final IPCC meeting, dominated by intense politics, occurred in Sundsvaal, Sweden. Diplomatic debate raged until the final hours of the meeting when the reports on science, impacts, and policy were all accepted.

The IPCC's major achievement was its report on a scientific assessment of climate change [14]. Based on the work of hundreds of scientists around the world and expertly led by the United Kingdom (UK), this publication critically reviewed the body of empirical evidence for global warming and the theoretical and empirical basis for climate modeling. While the report was careful to underscore the uncertainties in both empirical and theoretical knowledge, its conclusion was strong: "[T]he potential serious consequences of climate change on the global environment give sufficient reasons to begin adopting response strategies that can be justified immediately even in the face of significant uncertainties.”

The IPCC scientific assessment broke new ground by attempting to account for the impact of greenhouse gas on the "radiative" balance of the atmosphere using an index — the Global Warming Potential (GWP)—-that accounted for both the greenhouse effect of the gas and its lifetime in the atmosphere.

Among the three IPCC reports, the scientific assessment was a first-rate work product reflecting considerable international scientific debate and critical review. The other two reports on policy and impacts were uneven in quality. Given the uncertainties about regional climate change, the limited number of global impact studies, and the lack of time to conduct new analyses, the report of the working group on impacts became largely a compendium of ongoing impacts research and did not undergo much critical review.

The response strategies (policy) report prepared by the third working group was the most difficult to organize and write, since all participants knew it would have a significant impact on the upcoming negotiations of a climate convention. It was soon evident in the IPCC process that it was too early to achieve consensus on policy issues that were so sensitive to many countries and government agencies. The response strategies section discussed policy options and criteria for establishing their priorities, but made no recommendations for specific options or a timetable for their implementation. Instead, the final report called for international negotiations to start as quickly as possible after presentation of the assessment to the UN.

In December 1990, the United Nations General Assembly (UNGA) accepted IPCC's final report and established the Intergovernmental Negotiating Committee (INC) as the designated entity to lead development of a framework convention on climate. The UN resolution called for completion of the negotiations of the climate convention in time for the planned UN Conference on Environment and Development (UNCED) in Rio de Janeiro in June 1992.

The first IPCC assessment was critical for launching negotiations on an international agreement on climate change. The White House made it clear that unless the report provided strong rationale for action, the US would not support negotiation of an international agreement. Fortunately, the report was well-prepared and negotiations for an international agreement began.

\section{1992: Negotiating the UN Framework Convention on Climate Change (UNFCCC)}

In February 1991 temperatures in Washington broke a 108 -year-old record, reaching $70^{\circ} \mathrm{F}$. At this time the US 
was hosting the first UN International Negotiating Committee (INC) session in Chantilly, Virginia, near Dulles airport. The meeting was subtitled, "Protection of global climate for present and future generations of mankind". Negotiations began in Washington and would end after five intense sessions in New York in 1992, several months before the Rio meeting in June.

One of the earliest and longest debates in the negotiations was whether the "convention" should contain specific commitments (e.g., implementation mechanisms and targets and timetables for stabilizing and reducing emissions). The idea of specific commitments was not acceptable to the US, which was concerned about the cost of regulating greenhouse gases. Consequently, the Bush administration was unwilling to endorse binding protocols or targets for emission reduction.

The negotiations took place in 1990 and 1991, a time of euphoria in Europe where Communist governments in many countries were losing power and the European Community (EC) was moving quickly toward monetary and social union. This excitement carried over to environmental policy as many European ministers vied to make Europe the dominant influence on environmental issues. These ministers saw targets and timetables as a means of motivating their own governments (especially their trade and finance ministries) to move policies in a greener direction.

Regarding specific timetable and target commitments, early in the process Japan proposed a "Pledge and Review" concept whereby countries would unilaterally pledge specific actions. An international body would then review each country's performance, a mechanism intended to produce momentum towards stricter commitments and greater transparency. Environmental groups were not happy with this proposal, calling it "Hedge and Retreat". While the Japanese proposal was intensely debated, enthusiasm for the concept waned by the end of the meeting. The Group of 77 developing countries declared the concept dead on arrival.

Ironically, this idea of an international review is similar to the later agreement at the 2009 Copenhagen meeting to commit to implement individually- or jointly-quantified economy-wide emissions targets for 2020 that the countries would each set for themselves.

In early April 1992, approximately a week before the final INC negotiating session, the US released a white paper, "US Views on Climate Change," the result of difficult negotiations between EPA and DOE. The paper reanalyzed likely emission reductions from current US programs. The two agencies agreed that the US could reduce its emissions by 125 to 200 million metric tons of carbon by the year 2000 —within 1.5 to 6.0 percent of "stabilization". While environmentalists and other governments assumed that these results would allow the US to accept the EC's proposal for a target and timetable, senior White House officials remained unchanged in their opposition to the EC position.

In the final negotiations, the US maintained its position against binding targets and timetables. The Bush administration felt that a binding commitment to stabilize GHG emissions could force the US to adopt policy actions with unforeseen economic costs. Michael Boskin, chairman of President George H. W. Bush's Council of Economic Advisors, declared in 1992 that the international treaty on climate change was a "bet-your-economy decision" [15]. The US strongly believed that the EC position was untenable. Fortunately, the UK helped to resolve outstanding differences between the US and the EC; a final agreement was reached, but without binding targets.

In the end, the key goal of the UNFCCC was stabilizing greenhouse gas concentrations in the atmosphere at a level that would prevent dangerous anthropogenic interference with the climate system. Under the convention, governments would take three important steps:

- Gather and share information on greenhouse gas emissions, national policies and best practices,

- Launch national strategies for addressing greenhouse gas emissions and adapting to expected impacts, including developing financial and technological support to developing countries, and

- Cooperate in preparation for mitigation measures and adaptation to the impacts of climate change.

The treaty set no mandatory limits on greenhouse gas emissions for individual nations and contained no enforcement provisions, but it did provide for updates ("protocols") that would set mandatory emission limits. The first update would be the Kyoto Protocol (see next section.)

A key element of the UNFCCC is that parties should act to protect the climate system "on the basis of equity" and in accordance with the principle of "common but differentiated responsibility", which includes two fundamental elements: The common responsibility of the parties to protect the environment, or parts of it, at the national, regional, and global levels, and the need to take into account the different circumstances, particularly each nation's contribution to the problem and its ability to prevent, reduce, and control the threat. 
Upon signing the Climate Convention, President Bush said that the US would aim to reduce its greenhouse gas emissions to the 1990 level by the year 2000 .

\section{1997: Negotiating the Kyoto Protocol}

The UNFCCC included commitments to establish national action plans and voluntary measures to reduce greenhouse gas emissions to 1990 levels. However, it was soon concluded by parties to the UNFCCC that mandatory reduction of six major greenhouse gases was needed. The key dispute of the UNFCC was back on the table and the subject of negotiations of the Protocol.

The issue of setting specific emission targets for all countries was not easy to address. The main issues under debate were the amount of binding reductions in greenhouse gases to be required, whether developing countries should be part of the requirements for greenhouse gas limitations, and whether to include emissions trading and joint implementation (which would allow credit to be given for emissions reductions to a country that provides funding or investments in other countries).

During the negotiations, Vice President Al Gore introduced the idea of "cap and trade" as a way to introduce flexibility and thus reduce costs of reducing emissions. Cap and trade is an environmental policy tool that delivers results with a mandatory cap on emissions while providing the sources of emissions flexibility in how they comply. Successful cap and trade programs reward innovation, efficiency, and early action and provide strict environmental accountability without inhibiting economic growth.

Under terms of the final Protocol, the US would be committed to a target of reducing greenhouse gases to 7\% below 1990 levels during the so-called “commitment period” of 2008-2012. President Clinton signed the Protocol on November 12, 1998, but he did not submit the Protocol to the Senate for advice and consent because the Protocol's requirement for meaningful participation by developing countries in binding commitments limiting greenhouse gases had not been met.

Prior to negotiation of the Kyoto Protocol, the US Senate had passed a resolution asserting that the US should not sign any protocol that failed to include binding targets and timetables for both developing and industrialized nations, arguing that this "would result in serious harm to the economy of the United States". Hence action on the protocol would fall to the next administration and in March 2001, the President Bush rejected the Kyoto Protocol. A year later in February 2002, he announced a US policy for climate change that would rely on voluntary domestic actions to reduce the "greenhouse gas intensity" (ratio of emissions to economic output) of the US economy by $18 \%$ over the next 10 years.

The Kyoto Protocol was negotiated and implemented at a time of serious internal political conflict. From 2001 through 2008 the United States experienced a period of what I call "climate wars”, in which conflicts centered on the 1) the reality of climate science; 2) the economic impact of GHG regulations; and 3) the expanding role of EPA (Hecht, 2009) [15].

\section{2000-2010: Fighting the Climate Wars}

The climate wars started during the 2000 presidential campaign. While campaigning in Saginaw, Mich., George W. Bush promised to advance climate legislation, stating that "We will require all power plants to meet clean-air standards in order to reduce emissions of carbon dioxide within a reasonable period of time.” This was a surprising and encouraging position. While not a prominent theme in the Bush campaign as a whole, many observers saw this as a significant statement and departure from past Republican positions and were optimistic that a new era of environmental protection was about to begin.

Excited by this potential action, newly appointed EPA administrator Christine Todd Whit man announced to a meeting of the G-8 industrial countries in Trieste, Italy, that the US was committed to regulation of GHG emissions, assuring her counterparts that the US wanted a mandatory cap on $\mathrm{CO}_{2}$ emissions. The Joint Communiqué from this meeting expressed an international commitment to "take the lead by strengthening and implementing national programs and actions to reduce greenhouse gas emissions, as well as to promote and disseminate environmentally sound technologies and practices and renewable energy sources”.

Administrator Whitman was unaware of a behind-the-scenes effort led by Senators Chuck Hagel (later President Obama's Secretary of Defense), Jesse Helms, Larry Craig, and Pat Roberts to reverse the commitment she had announced. In a letter to the president, these senators highlighted their view that the commitment was unwise and was a serious threat to the US economy. 
The letter attracted the attention of Vice President Dick Cheney who, according to Barton Gellman, embarked on a plan to "walk the President away from his promise" [16]. Cheney's staff prepared a four-page memo "that would put the White House on record against the collective judgment of the world's climate scientists". Cheney's memo said that Bush should be nudged toward the position that the "current state of scientific knowledge about causes of and solutions to global warming is inconclusive. Therefore it would be premature at this time for the president to propose any specific policy or approach aimed at addressing global warming”.

President Bush accepted this approach and signed a letter responding to the senators that was prepared by Cheney's staff and given to the president without consulting with Administrator Whitman or others in government.

In a White House press statement, Bush said, "I do not believe, however, that the government should impose on power plants mandatory emissions reductions for carbon dioxide, which is not a 'pollutant' under the Clean Air Act”.

The fear, whether real or imagined, of negative economic impacts of climate change regulations is a critical hurdle to overcome. Since EPA was created, there has been continued debate about the economic impact of environmental legislation. In virtually all cases, the fear has been unfounded and environmental legislation has, in fact, benefited the economy. For example, studies by EPA on the impact of the Clean Air Act (CAA) and its amendments have yielded direct benefits to the American people vastly exceeding the costs of compliance [17].

In the area of climate change, assessing the full cost of actions including regulation and/or non-action is critical to ensure broad public support. Government leaders face serious challenges if the economy is weak. Economic recession in 1992 contributed to Bill Clinton's defeat of George H. W. Bush.

Following the Clinton presidency, the second Bush administration inherited an economy with a 1.6 percent GDP growth rate as the nation struggled to recover from the bursting of the high-tech bubble and the 9/11 attacks. Many business leaders and Washington politicians believed that the sluggish economy should not be laden with extra tax burdens on business, and in particular on the energy sector- the same economic concerns that are voiced today.

Based on such fears, a key element of the climate wars evolved with attacks on climate science that stressed scientific uncertainty and discrediting any scientific evidence that could support new federal legislation or regulations on carbon emissions. Such attacks were intended to preclude allowing carbon dioxide to be identified as a pollutant under the CAA or as an endangerment to human health.

This aversion to regulation had a significant impact on EPA. A key chapter of the Economic Report of the President submitted to Congress in 2002 focused on the cost of environmental regulations. The report warned that while there were significant achievements in the past decades reducing the most obvious risks to health and the environment, "there is evidence that further improvements in air quality would improve health and reduce mortality but these improvements might be extremely expensive". The same report underscored the scientific uncertainty of the effects of climate change:

We are uncertain about the effect of natural fluctuations on global warming. We do not know how much the climate could or will change in the future. We do not know how fast climate change will occur, or even how some of our actions could affect it. Finally, it is difficult to say with any certainty what constitutes a dangerous level of harm that must be avoided.

Attacks on climate science were growing and the biggest target was the IPCC. In 2001, the scientists preparing the IPCC assessment concluded that it was "likely" (which it defined as a probability greater than 66 percent) that climate change was caused by human activities. This report came under serious attack; deniers of climate change aimed to dispute any claim of human-induced climate change and hence any need for legislation. Six years later, the 2007 IPCC report raised the probability of human influences on climate to be "very likely" (indicating a probability greater than 90 percent) and detectable in observational records.

One graph in the 2001 IPCC report created a great controversy: it depicted a sharp rise in temperatures over the past 100 years, which the authors attributed to human activity. The graph became known as the "hockey stick" and became an element of the climate war when in June 2003, Rep. Joe Barton of Texas, the Republican chairman of the Subcommittee on Oversight and Investigations, requested Michael Mann, a key author of the IPCC report, to provide responses to eight detailed questions related to his credentials and past work. Details of this exchange and the subsequent political attacks on Mann are described in his 2012 book [18].

Unable to resolve these issues, Congress ultimately turned to the National Academy of Sciences to assess 
IPCC's reliability. The NAS report acknowledged some deficiencies in the analysis of data, but reaffirmed the quality and transparency of analyses used to support the IPCC assessment. Although the IPCC survived these attacks, many business and government leaders aiming to avoid new regulations adopted an operating plan of promoting the idea of scientific uncertainty and denying the certainty of global warming.

Toward the end of the Bush administration (2001-2009), signs of a possible positive response or a truce on dealing with climate change began to emerge. In 2007 dozens of the world's largest companies and non-government organizations (NGOs) came together and organized the US Climate Action Partnership (USCAP), which called for immediate action on climate change. Their "Call for Action Plan” was explicit:

Each year we delay action to control emissions increases the risk of unavoidable consequences that could necessitate even steeper educations in the future, at potentially greater economic cost and social disruption. Action sooner rather than later preserves valuable response options, narrows the uncertainties associated with changes to the climate, and should lower the costs of mitigation and adaptation. For these reasons, we, the members of the US Climate Action Partnership (USCAP) have joined together to recommend the prompt enactment of national legislation in the United States to slow, stop and reverse the growth of greenhouse gas (GHG) emissions over the shortest period of time reasonably achievable regulation advocated a mandatory cap-and-trade program [19].

The momentum provided by USCAP affected Congress, helping to slowly advance measures to create a climate bill. But not all business sectors supported GHG legislative options such as cap-and-trade or carbon taxes, and the Congressional debate resulted in a flood of published estimates of massive job losses and other economic impacts.

Once again, the sagging US economy and global economic recession ended the momentum in 2008-2010. In the first half of 2008, the GDP growth rate plunged into the negative range and, after rebounding slightly in 2009, it settled back to an annual growth rate of less than 2 percent. Many sectors of the US and international economies began to slowly recover from the financial collapse. The struggling economy increased the hesitance in some quarters to impose further economic costs in the short run and all but killed progress on climate legislation and international agreement while the deep recession continued.

The impact of the recession contributed to the failure of the UN-organized climate summit in Copenhagen in December 2009 and in December 2010 to the Cancun climate negotiations. While many reasons have been suggested for the failure of these conferences to advance toward a climate agreement, critics of climate science were quick to link that failure to scientific uncertainty and the expected economic costs of proposed measures.

While these wars raged on science and the economy, legal conflicts were also ongoing between states and the EPA on the failure of EPA to regulate GHG under the Clean Air Act. The question was whether EPA has the authority to regulate GHG as a pollutant. The seminal Supreme Court decision of 2007 affirmed that EPA has the authority to regulate $\mathrm{CO}_{2}$ emissions from automobiles. The decision resolved a war between several states and the federal government and had far-reaching impact on EPA, leading to its preparation and publication in 2009 of an “endangerment finding," which became the subject of another war between business and government [20].

\section{2007: Regulating $\mathrm{CO}_{2}$ as a Pollutant: The Supreme Court Decision}

The 2007 case began in 1998, when EPA’s General Counsel found that the agency possessed the authority to regulate the greenhouse gas carbon dioxide $\left(\mathrm{CO}_{2}\right)$ as an air pollutant. As a result, the International Center for Technology Assessment, Sierra Club, Greenpeace, and other environmental groups petitioned EPA in 1999 to set emissions limits for $\mathrm{CO}_{2}$ and other greenhouse gases emitted from new motor vehicles, arguing that it had a duty to do so under Section 202 of the CAA. The group's central argument was that $\mathrm{CO}_{2}$ was a pollutant whose impact on global warming was having a negative effect on human health and the environment. For three years, EPA failed to respond to the petition, resulting in a 2002 lawsuit brought by the environmental groups.

Under Section 202 of the CAA, EPA is required to set emission standards for "any air pollutant" from motor vehicles or motor vehicle engines "which in [the EPA administrator's] judgment cause[s], or contribute[s] to, air pollution which may reasonably be anticipated to endanger public health or welfare”.

In 2003, EPA argued that it lacked the authority under the CAA to regulate carbon dioxide and other GHGs for climate change purposes, and even if EPA did have such authority, it would decline to set GHG emissions standards for vehicles. In June 2003, Massachusetts, Connecticut, and Maine filed a lawsuit that argued that by failing to regulate carbon dioxide, the dominant cause of global warming, EPA was violating its mandatory duty under 
the CAA. The case moved to the US Court of Appeals for the D. C. Circuit. On July 15, 2005, a three-judge panel of the D. C. Circuit issued three separate opinions in the case. Two of the judges agreed to let EPA's administrative decision stand. The third judge issued a lengthy dissent agreeing with the Massachusetts position on all grounds. The case ultimately moved to the Supreme Court in November 2006.

On April 2, 2007, the Supreme Court found that greenhouse gases are air pollutants covered by the Clean Air Act. In this decision the court affirmed that "the harms associated with climate change are serious and well recognized”. For Massachusetts these harms include the loss of coastline from sea level rise resulting from global warming. Because EPA “does not dispute the existence of a causal connection between man-made gas emissions and global warming”, the court found, its “refusal to regulate such emissions 'contributes’ to Massachusetts' injuries”, thereby satisfying the traceability requirements.

In writing for the Supreme Court, Justice Stevens maintained that carbon dioxide and other GHGs are "air pollutants”, and that EPA's reasons for not regulating GHG emissions were insufficient. Four justices dissented (Roberts, Scalia, Thomas, and Alito), arguing that states did not have any special rights of status and that nothing the Court could do would address the "injuries complained of, because any decrease in emissions here will be overwhelmed many times over by emissions elsewhere in the world”.

Following the Court decision, President Bush issued an Executive Order in May 2007 that directed EPA and the Departments of Transportation, Energy, and Agriculture to coordinate in developing possible regulatory actions to address emissions from mobile sources contributing to global climate change. The first step in this complicated process was for EPA to examine the scientific evidence on whether carbon emissions and other greenhouse gases from mobile sources endanger public health and welfare under the Clean Air Act.

Finally on December 7, 2009, the EPA Administrator Lisa Jackson signed two distinct findings regarding greenhouse gases under section 202(a) of the Clean Air Act, noting that "current and projected concentrations of the six key well-mixed greenhouse gases-carbon dioxide $\left(\mathrm{CO}_{2}\right)$, methane $\left(\mathrm{CH}^{4}\right)$, nitrous oxide $\left(\mathrm{N}_{2} \mathrm{O}\right)$, hydrofluoro carbons (HFCs), perfluoro carbons (PFCs), and sulfur hexafluoride $\left(\mathrm{SF}^{6}\right)$ - in the atmosphere threaten the public health and welfare of current and future generations". And that "the combined emissions of these wellmixed greenhouse gases from new motor vehicles and new motor vehicle engines contribute to the greenhouse gas pollution which threatens public health and welfare”.

Many of the next steps would fall to the Obama administration.

\section{2010s: Responding to Extreme Events, the 2013 IPCC Assessment Report, and the 2014 US Climate Report}

From 1970 to the present the debate on climate change ranged on while GHG emissions in the atmosphere continued to rise (See Figure 1). The year 2010 was in fact a record year for $\mathrm{CO}_{2}$ emissions. Much of the 5.9\% global increase from 2009 to 2010 came from the world's largest fossil-fuel emitter, China, whose emissions rose by $10 \%$. Estimated carbon emissions from the United States in 2010 were up by almost 4\% over the 2009 estimates. Today, according to the latest World Meteorological Organization monitoring network, is just under 400 parts per million which is a level that most scientist feel can cause dramatic impacts.

Concerns about the negative impact of climate change raged on and actions now fell to President Obama. Unfortunately during his first term, the sagging US economy and global economic recession further heightened the climate wars and delayed any positive actions. Equally unfortunate was the fact that serious economic and human losses due to increasing extreme weather became a necessary driver of change.

According to the insurance giant Munich Re, in 2013 North America saw the world's sharpest increase in the number of natural catastrophes in 32 years, a trend that is consistent with the expected impacts of climate change. Insurance industries were deeply concerned. Franklin Nutter of the Reinsurance Association of America reported to Congress that in the 1980s the average number of natural catastrophes globally was 400 per year. In recent years, such events have averaged 1000 per year. North America has seen a fivefold increase in the number of catastrophic events since 1980, while Europe has seen a twofold increase [21].

The damaging floods caused by Superstorm Sandy in November 2012 buttressed the case that we are entering a new era of climate change. In the short and long term, business and government will need to adapt to the impacts of climate change and resolve the climate wars.

The science is compelling that human induced climate change is real. The IPCC Report in September 2013 highlighted that the climate system has warmed dramatically since the 1950s and affirmed with $95 \%$ to $100 \%$ 
confidence that human activity has caused climate change. The notion of human-induced climate change was further affirmed by scholarly data analysis of over 11,944 climate science abstracts published from 1991 to 2011 (Cook et al., 2013) which shows that the consensus for human-induced climate change grew steadily from 1996 to 2011 [22].

The US Third National Climate Assessment report of 2014, also concluded that the global warming of the past 50 years is primarily due to human activities, predominantly the burning of fossil fuels. The Assessment affirmed several key scientific, economic, and social impacts which have been debated for decades:

- Impacts related to climate change, already evident in many sectors, are expected to become increasingly disruptive across the nation throughout this century and beyond.

- Climate change threatens human health and well-being in many ways, including through extreme weather events and wildfire, decreased air quality, and diseases transmitted by insects, food, and water.

- Climate change poses particular threats to indigenous peoples' health, well-being, and ways of life.

- Some extreme weather and climate events have increased in recent decades, and new and stronger evidence confirms that some of these increases are related to human activities.

The Assessment also made the case for action:

- Planning for adaptation (to address and prepare for impacts) and mitigation (to reduce future climate change, for example, by cutting emissions) is becoming more widespread, but current implementation efforts are insufficient to avoid increasingly negative social, environmental, and economic consequences.

Do these analyses suggest that the war on climate change is over? Unfortunately some groups are still challenging the validity of climate science. This is exemplified by the ninth international conference on climate change sponsored by the group Heartland Institute. The July, 2014 meeting asserted that "the debate over the causes and consequences of global warming (or 'climate change') is one of the great controversies of the modern era. While environmental activists and some politicians claim 'the debate is over' and call for immediate action to reduce man-made greenhouse gas emissions, others say the science points to only a very small human impact - too small to warrant concern-and the costs of trying to prevent global warming far exceed the benefits” (See http://climateconference.heartland.org/). Hence building national consensus on the reality of climate change may still be a challenge.

While the likelihood of Congress acting on climate change remains limited, states, businesses and federal agencies can take needed actions to reduce GHG emissions and prepare to adapt to the impacts of climate change. President Obama is trying to implement his Climate Action Plan through existing legislation such as the Clean Air Act, as well as with new partnerships with states and the business community.

Over 40 years of climate study make it clear that while the economic impact of climate change will be unevenly distributed across the country, the country as a whole will be affected. Economic, health and social impacts of climate change will affect all people, regionally as well as nationally. In the world ahead enhanced attention will also have to be given give on the risks and vulnerabilities of the poor, the elderly, and the socially disenfranchised. The next era of climate change may very well be focused on its social impact.

\section{Conclusions and Next Steps}

The history described in this paper matched against the growing increase of greenhouse gases shown in Figure 1 demonstrates the need for broader acceptance of the reality of climate change and importance of early and effective actions to reduce greenhouse emissions. United Nations Secretary-General Ban Ki-moon invited heads of state and government along with leaders in business, finance, civil society, and local communities to a Climate Summit in September 2014 in New York aiming at catalyzing action by governments, business, and civil society. This meeting is scheduled one year before countries plan to meet again in 2015 with the aim of concluding a global climate agreement 2015 through the UNFCCC.

The UNFCCC meeting in 2015 will come while the US prepares for the 2016 presidential election. The issue of economic impact of climate change regulations may again be a contentious issue. EPA has proposed new regulations to reduce GHG emissions from power plants and is being challenged legally by several states. Following extensive public hearings, it will finalize its proposal in 2015 and give states a year to design their implementation plans. Every state will thus be involved in the extensive debate on climate change. EPA Administrator Gina McCarthy has said, upon the release of the proposed new regulations, that the high costs of climate inaction "are affecting American children and families today and it is important to limit carbon pollution". 
In the years ahead, it will be critical that businesses, states, and the public understand the full impacts and cost of climate change. Federal actions are moving in this direction as outlined in EO 13653, which urges federal agencies to engage and promote strong partnerships with all levels of government and tribal leaders to assess climate-related vulnerabilities and increase climate preparedness and resilience of communities in a cost-effective manner. Even before this EO, dozens of states and local governments began developing climate change plans. Industry support is evident from the Climate Declaration developed by CERES-sponsored Business for Innovative Climate and Energy Policy group, through which nearly 500 companies have recognized that tackling climate change can be an American economic opportunity. As those companies wrote to President Obama, "Our support is firmly grounded in economic reality. We know that tackling climate change is one of America's greatest economic opportunities of the 21st century and we applaud the EPA for taking steps to help the country seize that opportunity” [23].

From the lessons of history, especially the growing economic and social impacts of climate change seen in the last few years, three critical goals must be recognized and given priority:

1. Reduce conflict and create more effective collaboration among governments and among government, business, and society to address these trends. In a New York Times editorial of June 2014, marking the release of the report "Risky Business: The Economic Risks of Climate Change in the United States, [24] former Secretary of Treasury Henry Paulson wrote, "There is a time for weighing evidence and a time for action" and that action on climate change is now a "crisis we can't afford to ignore". Paulson argued that "we need to craft national policy that uses market forces to provide incentives for the technological advances required to address climate change" [25].

2. Government's role must include regulations, which can prompt innovation, while their absence can delay progress. Fear of regulations by some business and political leaders can carry a high cost. After initially opposing cap-and-trade, some businesses moved towards a collective judgment to support this approach, driven partly by their expectation that President Obama would push for strong legislation supporting cap-and-trade and that Congress would pass such legislation. But the latter did not happen.

3. A powerful demonstration of the impact of the failed legislation was the decision of the American Electric Power (AEP) to put on hold its \$668-million project to build a carbon-capture system for a coal plant in West Virginia. With no national climate plan and a weak economy, AEP's incentive disappeared.

4. Promote greater public understanding of the impacts of climate change on land use, agricultural production, human health, and economic well-being. The public must fully understand the financial implications of climate change and encourage business-government collaboration to address the impacts of global warming. The economic impacts of climate change will impact all sectors of the economy, especially agriculture, energy, and transportation. The economic impacts will be unevenly distributed across regions and within the economy and society. Regional as well as national attention should be paid to the vulnerabilities of the poor, the elderly, and the socially disenfranchised.

5. The lessons of history also suggest that in the long term, government and business must also act to: Anticipate risk, understand early warning signals, and take steps to avoid, reduce, and mitigate future problems. We cannot respond to catastrophic problems only after a catastrophe has occurred. We don't want a world where we need to rebuild our institutions because of environmental or economic disasters. It is here that the concept of "resilience" is a growing element of adapting to climate change. The capacity of a system to absorb disturbance and still retain its basic function and structure is called resilience. The concept of resilience is evident to cities and regions in responding to increased natural disasters. The concept is equally relevant to the business world as well. A new emphasis on "resilient dynamism" as a business imperative was a feature of the 2013 World Economic Forum in Davos. The business world recognizes the need for resilience in a world of ever-increasing complexity, connectivity, and turbulence.

The history and analysis in this paper make clear that the environmental problem that society now faces is not the absence of scientific knowledge, but rather the need to develop policies and approaches that promote economic development with minimum impact on the environment. More effective government-government and government-business_-society collaboration is needed to address today's problems while avoiding future ones.

\section{Disclaimer}

Views expressed in this article are those of the author and do not necessarily reflect the views or policies of the US 
Environmental Protection Agency (EPA). Mention of trade names or commercial products does not constitute agency endorsement or recommendation for use.

\section{Acknowledgements}

The author gratefully thanks David Piantanida, Frank Princiotta, Joseph Fiksel, Andy Miller, and Edward Fallon for their valuable suggestions.

\section{References}

[1] Moynihan, D. (1969) Memo on $\mathrm{CO}_{2}$ and Warming. Nixon Library. Press Release. http://www.huffingtonpost.com/2010/07/03/moynihan-nixon-global-warming_n_634526.html

[2] Von Neumann, J. (1955) Can We Survive Technology? Fortune, June.

[3] Oreskes, N. (2007) The Long Consensus of Climate Change. Washington Post. February 1. http://www.washingtonpost.com/wp-dyn/content/article/2007/01/31/AR2007013101808.html

[4] Kukla, G.J., Matthews, R.K. and Mitchell, J.M. (1972) Guest Editorial: The End of the Present Interglacial. Quaternary Research, 2, 261-269. http://dx.doi.org/10.1016/0033-5894(72)90046-4

[5] Reeves, R., Gemmill, D., Livezey, R. and Laver, L. (2004) Global Cooling and the Cold War-And a Chilly Beginning for the United States Climate Analysis Center. http://www.meteohistory.org/2004polling_preprints/docs/abstracts/reeves\&etal_abstract.pdf

[6] NAS (1979) Carbon Dioxide and Climate: A Scientific Assessment. http://web.atmos.ucla.edu/ brianpm/download/charney report.pdf

[7] World Meteorological Organization (1979) World Climate Program. http://www.wmo.int/pages/prog/wcp/wcp.html

[8] National Climate Program Office (1980) National Climate Program: Five-Year Plan. https://archive.org/stream/nationalclimatep00unit/nationalclimatep00unit_djvu.txt

[9] Seidel, S. and Keyes, D. (1983) Can We Delay a Greenhouse Warming? The Effectiveness and Feasibility of Options to Slow a Build-Up of Carbon Dioxide in the Atmosphere. Strategic Studies Staff, Office of Policy Analysis, US EPA, Washington DC.

[10] EPA (1989) The Potential Effect of Global Climate Change on the United States. Report to Congress. US EPA, Washington DC.

[11] EPA (1990) Policy Options for Stabilizing Global Climate. Report to Congress: Main Report. EPA, Washington DC.

[12] Agrawala, S. (1997) Explaining the Evolution of the IPCC Structure and Process. Belfer Center for Science and International Affairs of the Kennedy School of Government, Harvard University. Discussion Paper E-97-05, Cambridge.

[13] Hecht, A. and Tirpak, D. (1995) Framework Agreement on Climate Change: A Scientific and Policy History. Climatic Change, 29, 371-402. http://dx.doi.org/10.1007/BF01092424

[14] Houghton, J., Jenkins, G.J. and Ephraums, J.J. (Eds.) (1988) Climate Change: The IPCC Scientific Assessment. WMO, UNEP. Cambridge University Press, London.

[15] Hecht, A. (2009) Resolving the Climate Wars. Sustainable Development Law \& Policy, 9, 4-15.

[16] Gellman, B. (2009) Angler: The Cheney Vice Presidency. Penguin Press, New York.

[17] EPA, Office of Air and Radiation (2011) The Benefits and Costs of the Clean Air Act from 1990 to 2020. Final Report, US EPA, Washington DC.

[18] Mann, M. (2012) The Hockey Stick and the Climate Wars: Dispatches from the Front Line. Columbia University Press, New York.

[19] United States Climate Action Partnership (USCAP) (2007) A Call for Action. http://us-cap.org/USCAPCallForAction.pdf http://www.us-cap.org/about-us/our-report-a-call-for-action

[20] EPA (2013) Endangerment and Cause or Contribute Findings for Greenhouse Gases under Section 202(a) of the Clean Air Act. http://www.epa.gov/climatechange/endangerment

[21] Nutter, F. (2013) Climate Change: It’s Happening Now. Testimony to Congress, 18 July 2013. http://www.epw.senate.gov/public/index.cfm?FuseAction=Files.View\&FileStore id=f86b767e-7a71-48b4-8eef-7bd9a d1d 3884

[22] Cook, J., Nuccitelli, D., Green, S., Richardson, M., Winkler, B., Painting, R., Way, R., Jacobs, P. and Skuce, A. (2013) Quantifying the Consensus on Anthropogenic Global Warming in the Scientific Literature. Environmental Research 
Letters, 8, Article ID: 024024. http://iopscience.iop.org/1748-9326/8/2/024024/ http://dx.doi.org/10.1088/1748-9326/8/2/024024

[23] Business for Innovate Climate and Energy Policy (2014) Unilever, VF Corp., and Mars Incorporated Join 173 Companies and Investors in Supporting EPA's New Carbon Standard. http://www.ceres.org/bicep

[24] Paulson, H., Bloomberg, M. and Steyer, T.P. (2014) Risky Business: The Economic Risks of Climate Change in the United States. http://riskybusiness.org/

[25] Paulson Jr., H.M. (2014) The Coming Climate Crash: Lessons for Climate Change in the 2008 Recession. New York Times, 21 June 2014.

http://www.nytimes.com/2014/06/22/opinion/sunday/lessons-for-climate-change-in-the-2008-recession.ht $\underline{\mathrm{ml} ? \mathrm{r}=2 \#}$ 
Scientific Research Publishing (SCIRP) is one of the largest Open Access journal publishers. It is currently publishing more than 200 open access, online, peer-reviewed journals covering a wide range of academic disciplines. SCIRP serves the worldwide academic communities and contributes to the progress and application of science with its publication.

Other selected journals from SCIRP are listed as below. Submit your manuscript to us via either submit@scirp.org or Online Submission Portal.
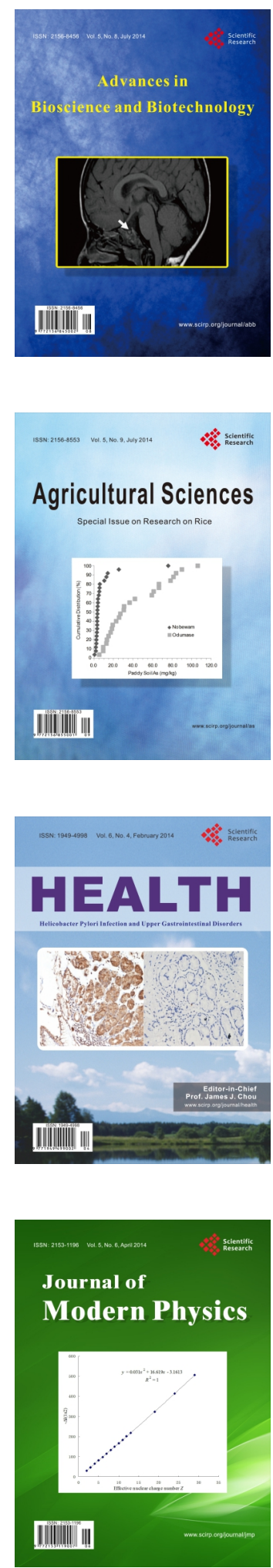
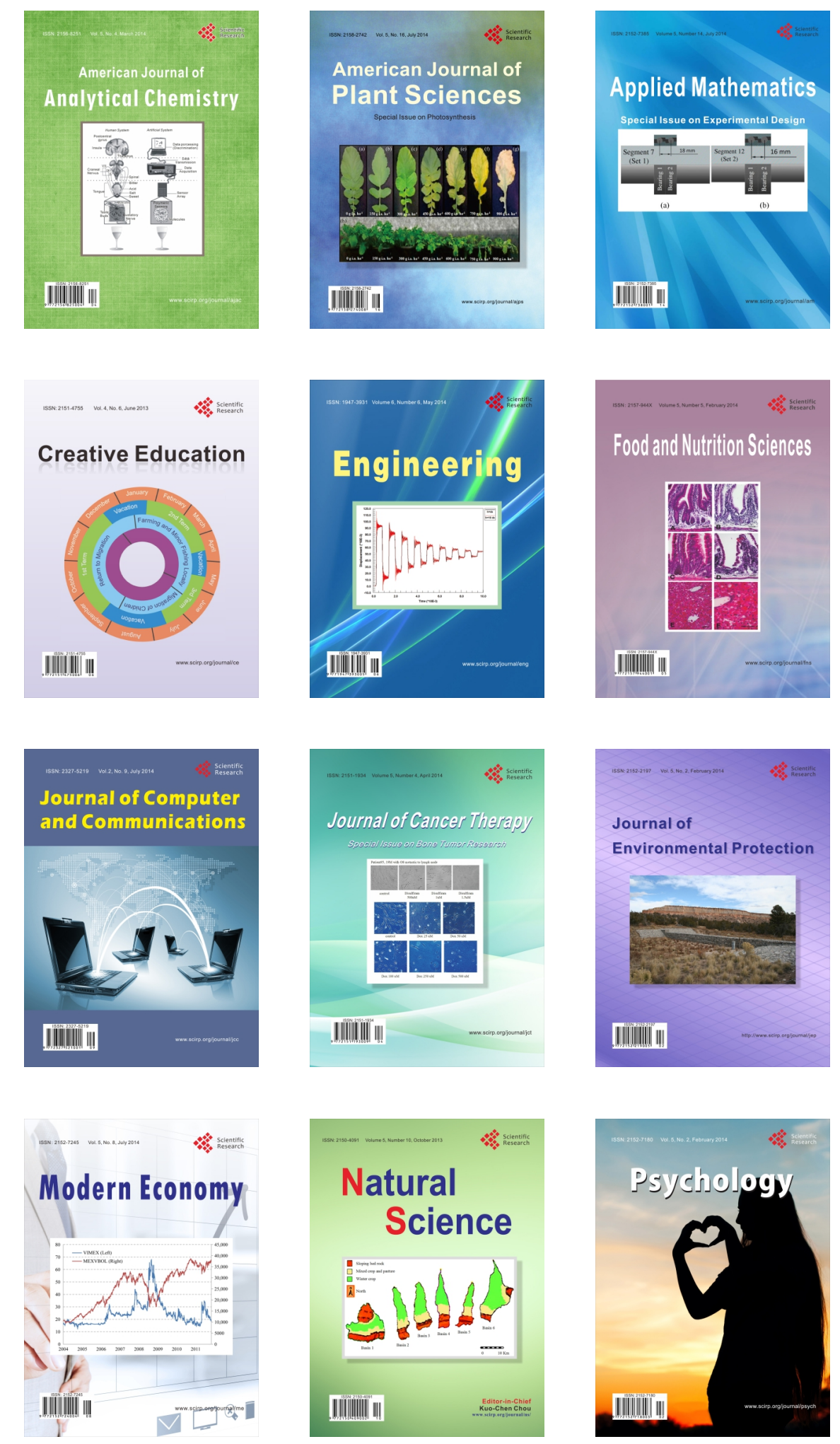